\title{
KOMUNIKASI PERSUASIF PEKERJA SOSIAL DALAM PROSES ADAPTASI IMIGRAN ANAK TANPA PENDAMPING DI INDONESIA
}

\author{
Stefani Made Ayu, Christin Agustina Purba \\ FHISIP Universitas Terbuka, FISIP Universitas Prima Indonesia \\ stefanimadeayu@ecampus.ut.ac.id, christin.agustina@gmail.com
}

\begin{abstract}
ABSTRAK
Indonesia merupakan salah satu negara transit sementara bagi imigran yang ingin resettlement ke negara ketiga (tujuan). Imigran illegal yang datang tanpa pendampingan dan berusia dibawah 18 tahun disebut dengan istilah UAM (Un Accompany Minor). Selama berada di Indonesia mereka ditampung selain di rumah detensi Imigrasi juga ditempatkan di akomodasi khusus yang menangani anak tanpa pendampingan. Penelitian ini bertujuan untuk mengkonstruksikan bagaimana proses komunikasi persuasif yang terjalin antara petugas yang melayani dalam akomodasi khusus UAM, dan bagaimana proses adaptasi UAM terhadap lingkungan sekitar di kota Medan. Hasil penelitian ini mengkonstruksikan bagaimana proses komunikasi persuasif yang dilakukan oleh petugas sosial kepada UAM di Dinsos Comunnity House (DCH) tidak berhasil karena faktor noise, kurangnya pemahaman UAM terhadap masa depan mereka dan pekerja sosial tidak memiliki kewajiban untuk membuat UAM hingga berhasil diterima wawancara oleh negara dunia ketiga. Adaptasi UAM terhadap lingkungan sekitar dibatasi oleh pekerja sosial dan petugas DCH karena menghindari kecemburuan sosial dan konflik dengan warga lingkungan sekitar diluar DCH. UAM sendiri sedang berusaha untuk beradaptasi dengan sesamanya di DCH yang sekarang menampung UAM dari 4 negara, sejauh ini adaptasi tersebut sedang berjalan tanpa konflik besar.
\end{abstract}

Kata Kunci: Komunikasi Persuasif, Adaptasi Budaya 


\section{PENDAHULUAN}

Negara Indonesia merupakan negara transit sementara yang banyak ditempuh oleh para pengungsi dari negara lain yang ingin mempermudah proses reshuttement ke negara ketiga (tujuan). Selain mendapatkan hak-haknya, pengungsi juga dibebankan beberapa kewajiban seperti menghormati dan mematuhi hukum yang berlaku di negara ia berada dan kewajiban membayar pajak dan biaya-biaya fiskal lainnya (Mulhadi, 2014: 55). Menurut Mulhadi, diperlukan kerjasama internasional dalam menangani dan berhubungan dengan imigran, yaitu antara Komisi khusus PBB yang menangani pengungsi (UNHCR), organisasi internasional yang menangani imigran (IOM) bersama Dinas sosial dan Lembaga Imigrasi Indonesia.

Imigran illegal yang datang ke Indonesia ada yang sudah dewasa ataupun keluarga dan anak-anak yang berada dibawah usia 18 tahun. Anak-anak tersebut juga ada yang datang tanpa pendampingan orang dewasa, yang disebut dengan istilah UAM (Un Accompany Minor). Selama berada di Indonesia mereka ditampung selain di rumah detensi Imigrasi juga ditempatkan di akomodasi khusus yang menangani UAM. Dalam akomodasi khusus UAM ditangani berbeda dengan imigran lainnya, karena adanya undang-undang perlindungan anak. Proses penanganan imigran anak diperlukan perhatian khusus dan komunikasi persuasif terhadap mereka, terlebih karena perbedaan latar belakang budaya dari tempat asal mereka tinggal dengan budaya di Indonesia.

Para Imigran anak yang berusia dibawah 18 tahun memiliki 3 kemungkinan masa depan yang dapat mereka raih ketika mereka menginjak usia 18 tahun, yaitu 1) lolos seleksi untuk mendapatkan suaka di negara penampung, terutama negara dunia ketiga seperti negara Australia, Kanada, dan Amerika Serikat; 2) tidak lolos seleksi untuk mendapatkan suaka di negara penampung, tetap berada di Indonesia dan bergabung dalam penampungan kategori dewasa/berkeluarga dibawah koordinasi IOM Indonesia; 3) adanya harapan bahwa imigran anak yang datang tanpa pendamping mendapatkan perlindungan dan dapat melanjutkan hidup mereka dalam kualitas yang lebih baik dan pasti di negara yang lebih aman daripada negara asal mereka. Pekerja sosial di penampungan akomodasi khusus harus dapat memberikan pembekalan dan berupaya membantu anak-anak yang berada dalam pengawasan mereka untuk dapat beradaptasi dalam lingkungan yang baru.

Pekerja sosial bertugas dalam memperhatikan dan memberikan support bagi UAM. Salah satu hasil review penelitian terdahulu (Englund, 2011) mengungkapkan bahwa para pekerja sosial yang ahli dalam komunikasi lintas budaya dan memiliki kemampuan lebih dalam memberi dukungan bagi anak-anak yang rentan dapat menyuarakan pendapat yang penting dalam menceritakan permasalahan serta memperjuangkan kepentingan imigran anak. 
Beberapa penelitian yang digunakan sebagai review penelitian terdahulu yaitu: "Eternal Return: Present-Day Probelms Associated with Social Reintegration of Ukrainan Labor Migrants Arriving in Ukraine from the EU (based on sociological research result" ditulis oleh Katerina Ivashchenko dalam laporan penelitian CARIM-East tahun 2013. Penelitian ini melihat Ukraina sebagai negara transit bagi para imigran yang lebih dari $70 \%$ datang dari Rusia, Belarus dan Moldova menuju ke Uni Eropa. Ketidakstabilan ekonomi dan banyaknya tingkat pengangguran semakin membuat meningkatnya jumlah migran yang ingin meningkatkan kesejahteraan. Hasil penelitian ini mengungkapkan bahwa 1) ada beberapa hal yang membuat migran belum tentu ingin kembali ke daerah asalnya; 2) migrasi ke Uni Eropa dilakukan karena keinginan untuk meningkatkan status kelas, kesejahteraan, mendapatkan pengalaman baru dan ikut dalam pasar pekerja internasional maupun nasional; 3) migrasi kembali ke negara asal dilakukan dengan motivasi untuk kembali bertemu dengan keluarga, untuk menemukan kembali lingkungan yang umum dikenal, memiliki kembali modal sosial, modal budaya dan modal material serta menemukan prospek kehidupan yang baru; Masalah migran menjadi masif dan sistemik, namun kesuksesan dan kegagalan dalam penangannnya lebih disebabkan pada hal otentik (individual) dan karena pelaksanaan penanganan yang masih berkendala.

"Adaptasi Budaya Etnis Rohingya dalam Budaya Masyarakat Aceh Timur dan Kota Langsa" ditulis oleh Bayu Pratam (2016), mengangkat bagaimana proses adaptasi budaya etnis Rohingya dengan masyarakat Aceh ketika berada di penampungan sementara yang berada di Aceh. Adapatasi berlangsung dengan baik dan tidak ada hambatan yang serius meskipun sempat mengalami culture shock pada awal kedatangannya. Adaptasi budaya terjadi dalam beberapa aspek kebudayaan antara lain di bidang bahasa, cara berpakaian, kuliner dan cara beribadah. Menurutnya adaptasi budaya berlangsung dalam suatu perjalanan waktu yang tidak dapat diperhitungkan dengan tepat. Kurun waktunya bisa cepat, bisa juga lambat atau justru berakhir dengan kegagalan tergantung daripada masing-masing individu yang mengalami proses adaptasi itu.

Peran pekerja sosial yang menangani UAM sangatlah penting. Kemampuan komunikasi dari pekerja sosial menjadi salah satu faktor pendukung anak-anak imigran tanpa pendamping agar dapat memperoleh hak asasinya sebagai manusia dan juga memperjuangkan masa depan. Dari fenomena tersebut, penelitian ini ingin menggambarkan konstruksi bagaimana proses komunikasi persuasif yang terjalin antara petugas yang melayani dalam akomodasi khusus imigran anak tanpa pendamping, serta menjelaskan upaya apa saja yang dilakukan oleh para pekerja sosial untuk berkomunikasi dengan para imigran ini yang sebagian besar tidak dapat berbahasa Inggris ataupun berbahasa Indonesia. Berdasarkan uraian latar belakang diatas, peneliti dapat merumuskan masalah yang ada sebagai berikut: 1) Bagaimana proses komunikasi persuasif yang dilakukan oleh pekerja sosial dengan imigran anak tanpa pendamping dalam penampungan akomodasi khusus yang berada di kota Medan; dan 2) Bagaimana 
proses adaptasi imigran anak tanpa pendamping dalam penampungan akomodasi khusus terhadap lingkungan sekitar di kota Medan.

De Vito (2011) menyatakan bahwa usaha melakukan persuasi memusatkan perhatian pada upaya mengubah atau memperkuat sikap atau kepercayaan khalayak atau pada upaya mengajak mereka bertindak dengan cara tertentu. Persuasi sebagai proses komunikasi bertujuan untuk memperoleh respon dengan pesan-pesan verbal dan non verbal dilakukan secara halus dan manusiawi agar komunikan melaksanakan sesuatu dengan senang hati. Persuasif dapat dilakukan secara emosional maupun rasional. Menurut Sumirat \& Suryana (2014) melalui rasional, orang dapat dibujuk untuk mengubah kognitifnya seperti misalnya ide, konsep, hingga terbentuk keyakinan. Sedangkan melalui emosi, orang dapat dibujuk untuk bersimpati, berempati terhadap sesuatu. Proses persuasif dapat mengubah minat seseorang. Kedua proses tersebut menusut Mar'at dalam Sumirat \& Suryana (2014) diawali dengan perhatian dari si penerima pesan.

Unsur-unsur dari proses komunikasi persuasif menurut Sumirat \& Suryana (2014) yaitu:

\section{a. Persuader}

Pihak yang menyampaikan pesan, memiliki tujuan untuk mengubah sikap/pendapat orang lain, dengan cara verbal maupun non verbal

b. Persuadee

Pihak yang menjadi target pesan yang disampaikan persuader

c. Persepsi

Persepsi persuadee terhadap persuader dan pesan yang disampaikan, yang mempengaruhi efektif tidaknya proses komunikasi persuasif; dipengaruhi oleh internalisasi persuadee mengenai persuader dan pesan

d. Pesan persuasif

Pesan persuasif adalah usaha sadar untuk mengubah perilaku, pikiran dan tindakan dengan memanipulasi motif-motif ke arah yang sudah ditetapkan. Namun demikian, manipulasi disini bukan mengubah dengan mengurangi atau menambah fakta sesuai konteksnya, namun cenderung memanfaatkan fakta lain yang dapat mendukung agar persuadee menerima pesan dan mengikuti maksud pesan yang disampaikan.

e. Saluran Persuasif

Merupakan media atau perantara ketika persuader mengirimkan pesan yang berasal dari sumber awal untuk tujuan akhir. Saluran (channel) digunakan oleh persuader untuk komunikasi dengan pihak persuadee secara formal maupun non formal, tatap muka maupun menggunakan media.

f. Umpan Balik dan Efek

Merupakan reaksi / efek yang terjadi pada persuader yang datang dari hasil persuasi yang dilakukan oleh persuader. Umpan balik internal merupakan reaksi persuadee terhadap pesan yang disampaikan, sedangkan umpan balik eksternal adalah reaksi yang terjadi pada persuadee karena pesan tidak 
dipahami atau tidak diterima oleh persuadee. Efek yang disebut diatas merupakan perubahan yang terjadi pada persuadee

Dalam sebuah proses komunikasi persuasif yang sederhana menurut Herbert W. Simons dalam Sumirat \& Suryana (2014) tergambar dalam beberapa proses antara lain: (1) tahap pemahaman, dimana persuader menyeleksi berbagai alternatif pilihan dari persepsi, pikiran dan perasaannya untuk disampaikan; (2) tahap encoding, dimana pesan dibentuk secara linguistik kemudian dipindahkan ke dalam stimulus fisikal yang dapat berjalan melalui ruang; (3) tahap decoding, dimana persuadee memindahkan kembali stimulus fisikal ke dalam bentuk-bentuk yang disepakati secara sematik; dan (4) tahap evaluasi, dimana persuadee memperoleh ketidakcocokan antara pesan yang ia terima dengan apa yang ia pikirkan dan rasakan, pada tahapan ini feedback diberikan kepada persuader. Perbedaan dengan proses komunikasi umumnya, pada proses komunikasi persuasif persuader memiliki target atau capaian tertentu terhadap feedback atau efek yang diberikan oleh persuadee.

Menurut Gudykunt \& Kim (2003) ada dua tahap adaptasi, yaitu cultural adaptation dan cross-cultural adaptation. Cultural adaptation merupakan proses dasar komunikasi yaitu di mana ada penyampai pesan, medium dan penerima pesan, sehingga terjadi proses encoding dan decoding. Proses ini didefinisikan sebagai tingkat perubahan yang terjadi ketika individu pindah ke lingkungan yang baru. Terjadi proses pengiriman pesan oleh penduduk lokal di lingkungan baru tersebut yang dapat dipahami oleh individu pendatang, hal ini dinamakan enculturation. Enculturation terjadi pada saat sosialisasi.

Gambar 1.

Hubungan antara istilah kunci dalam Adaptasi Antar Budaya

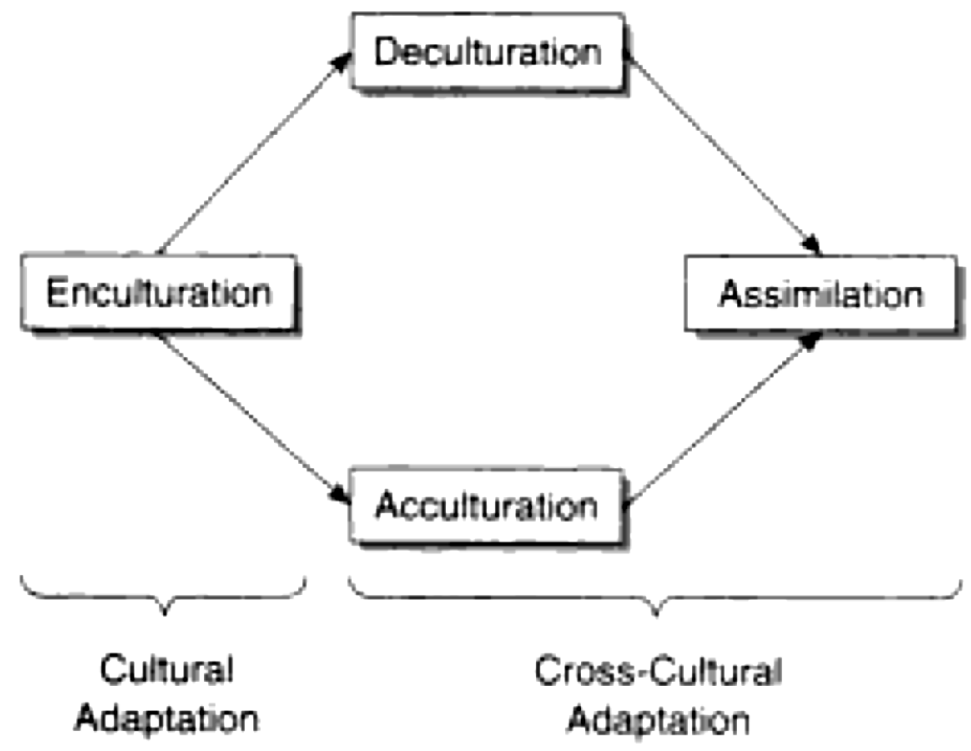

Sumber: Kim, 2001 
Tahap yang kedua adalah cross-cultural adaptation. Cross-cultural adaptation meliputi tiga hal yang utama. Pertama, acculturation. Proses ini terjadi ketika individu pendatang yang telah melalui proses sosialisasi mulai berinteraksi dengan budaya yang baru dan asing baginya. Seiring dengan berjalannya waktu, pendatang tersebut mulai memahami budaya baru itu dan memilih norma dan nilai budaya lokal yang dianutnya. Walaupun demikian, pola budaya terdahulu juga mempengaruhi proses adaptasi. Pola budaya terdahulu yang turut mempengaruhi ini disebut deculturation yang merupakan hal kedua dari proses adaptasi. Perubahan akulturasi tersebut mempengaruhi psikologis dan perilaku sosial para pendatang dengan identitas baru, norma dan nilai budaya baru. Inilah yang kemudian memicu terjadinya resistensi terhadap budaya baru, sehingga bukannya tidak mungkin pendatang akan mengisolasi diri dari penduduk lokal.

Namun, harus kembali dipahami bahwa dalam proses adaptasi ada yang berubah dan ada yang tidak berubah. Gudykunts dan Kim (2003) menyatakan bahwa kemungkinan individu untuk mengubah lingkungan sangatlah kecil. Hal tersebut dikarenakan dominasi dari budaya penduduk lokal yang mengontrol kelangsungan hidup sehari-hari yang dapat memaksa para pendatang untuk menyesuaikan diri. Hal yang ketiga adalah tahap paling sempurna dari adaptasi, yaitu assimilation (Gudykunts dan Kim, 2003). Assimilation adalah keadaan dimana pendatang meminimalisir penggunaan budaya lama sehingga ia terlihat seperti layaknya penduduk lokal. Secara teori terlihat asimilasi terjadi setelah adanya perubahan akulturasi, namun pada kenyataannya asimilasi tidak tercapai secara sempurna. Menurut Kim, proses adaptasi antar budaya merupakan proses interaktif yang berkembang melalui kegiatan komunikasi individu pendatang dengan lingkungan sosial budayanya yang baru. Adaptasi antar budaya tercermin pada adanya kesesuaian antara pola komunikasi pendatang dengan pola komunikasi yang diharapkan atau disepakati oleh masyarakat dan budaya lokal/setempat. Begitupun sebaliknya, kesesuaian pola komunikasi inipun menunjang terjadinya adaptasi antar budaya.

Pada penelitian ini, peneliti melihat proses komunikasi persuasif yang dilakukan oleh pekerja sosial (persuader) sebagai salah satu bentuk sosialisasi antara UAM (persuadee) terhadap lingkungan yang baru atau proses enculturation, agar mempermudah proses adaptasi budaya. Pesan persuasif yang disampaikan oleh pekerja sosial/persuader adalah pesan-pesan yang bertujuan agar proses adaptasi UAM berhasil sehingga mereka dapat memperbaiki kehidupan mereka di lingkungan yang baru. 
Gambar 2.

Kerangka Konsep penelitian

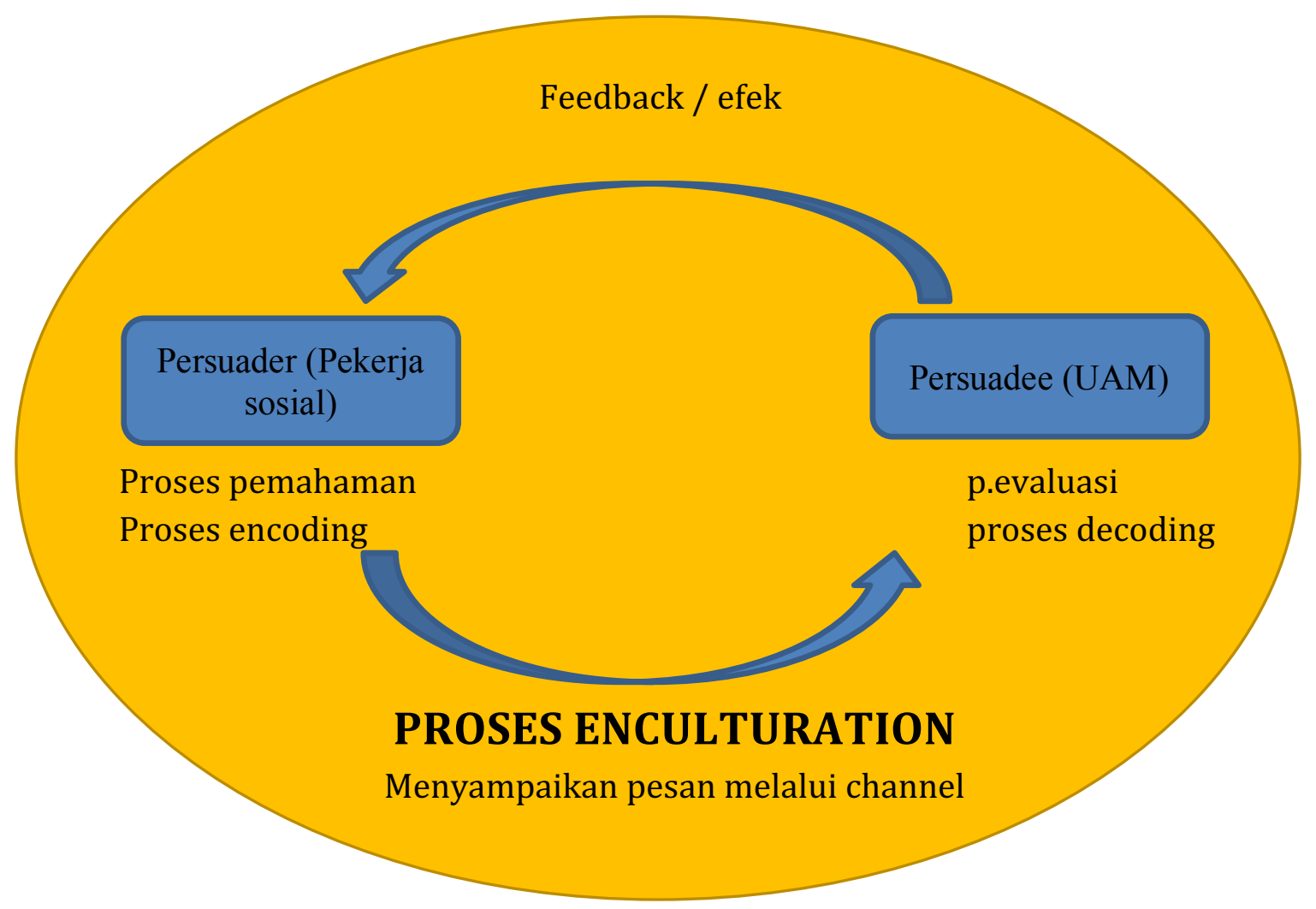

\section{METODE PENELITIAN}

Penelitian ini merupakan penelitian kualitatif yang menggunakan paradigma konstruktivisme. Dalam mengkaji masalah ini penulis menggunakan teknik analisa data kualitatif karena data yang diperoleh tidak bisa diukur secara statistik-matematis. Deduktif dari transkrip wawancara dioleh menjadi axial coding dan selective coding hingga menghasilkan temuan data signifikan. Data primer diperoleh dari wawancara mendalam terhadap 5 UAM dari 4 negara yaitu Afganistan ( 2 anak), Srilanka, Sudan dan Somalia, dan pekerja sosial serta petugas di Dinsos Community House kota Medan. Data sekunder didapat dari peraturan di DCH dan laporan kegiatan tahunan DCH.

\section{HASIL DAN PEMBAHASAN}

Dari hasil selective coding atas transkrip wawancara terhadap 3 orang pekerja sosial, 2 orang satpam, 2 orang ibu asuh / caretaker dan 5 UAM dari 4 negara (Afganistan, Sri Lanka, Somalia dan Sudan) yang berada di DCH, ditemukan beberapa hasil temuan signifikan, yaitu:

1. Pekerja sosial sering memberikan pesan persuasif kepada UAM mengenai pengembangan diri dan hal yang harus mereka lakukan agar dapat beradaptasi 
dengan budaya di Indonesia tanpa mengundang konflik di lingkungan sekitar DCH.

2. DCH baru menerima UAM dari 3 negara konflik selain Afganistan, yaitu Somalia, Sri Lanka dan Sudan. Sebelumnya di tahun 2015-2017 DCH memberikan layanan dan fasilitas kepada UAM dari Afganistan.

3. Pekerja sosial membatasi sosialisasi UAM dengan warga Indonesia di luar lingkungan DCH karena menghindari konflik dan menjaga ketertiban lingkungan.

4. Pola komunikasi persuasif yang sudah dilakukan pekerja sosial yaitu: 1. pembuatan peran, 2. memberikan reward, 3. pendekatan personal melalui kesamaan gender. Hasil wawancara menunjukan bahwa UAM tidak merasa bahwa persuasif yang disampaikan oleh pekerja sosial atau petugas DCH lainnya efektif bila tidak menggunakan bahasa yang mereka pahami. Sedangkan petugas DCH menyatakan bahwa pendekatan pemberian reward dirasa tidak efektif karena UAM tidak konsisten.

5. UAM merasa bahwa persuasif yang disampaikan oleh pekerja sosial akan lebih berhasil bila disampaikan dengan bahasa Inggris/ bahasa yang dapat mereka pahami.

6. Dari 39 anak, hanya 10 orang yang bisa berbahasa Inggris. Dari seluruh petugas DCH hanya 3 orang yang fasih berbahasa Inggris.

7. Di Tahun 2017 hanya 1 UAM yang dipanggil wawancara dan lolos seleksi dari UNHCR untuk bekerja di negara lain.

8. Sebagian besar UAM masih belum bisa beradaptasi dengan budaya lokal di Medan.

Berdasarkan hasil data wawancara, dapat dikonstruksikan bahwa pekerja sosial di DCH khususnya pekerja sosial memberikan pesan persuasif kepada UAM untuk dapat menyesuaikan diri/beradaptasi dengan budaya di Indonesia. Pada proses pemahaman pesan, persuader (pekerja sosial) lebih mengutamakan budaya yang bertujuan agar UAM tidak berkonflik dengan masyarakat lingkungan sekitar DCH dalam pemilihan tujuan pesan persuasifnya. Namun karena takut memicu konflik dengan masyarakat lingkungan sekitar, pekerja sosial bersepakat untuk membatasi sosialisasi UAM terhadap masyarakat luar (proses enculturation). Setelah itu, prioritas kedua pesan yang ingin disampaikan oleh pekerja sosial sebagai persuader adalah agar UAM bersopan santun yang baik sesuai adat istiadat di Indonesia. Prioritas lainnya adalah agar UAM lebih rajin dalam mengembangkan diri mereka selama di DCH. Prioritas ini terbentuk karena memang tidak ada kewajiban pekerja sosial untuk membuat UAM lolos dalam wawancara penerimaan pekerja ke negara dunia ketiga. Keputusan dalam hal wawancara untuk dapat menjadi pekerja ke negara yang menerima UAM atau imigran dewasa tersebut bukan wewenang DCH atau pekerja sosial, dan pekerja sosial hanya bertanggung jawab dalam memberikan fasilitas kepada UAM untuk mengembangkan diri, tanpa memaksa UAM.

Pada proses encoding, persuader (pekerja sosial dan pekerja di DCH umumnya) hanya menyampaikan melalui lisan. Berdasarkan hasil temuan data signifikan, terdapat noise 
dalam proses encoding yaitu kendala bahasa. Noise ini juga menjadi kendala dalam proses decoding oleh persuadee (UAM). Tidak semua pekerja sosial fasih berbahasa Inggris dan tidak ada satupun dari pekerja sosial yang dapat berbahasa yang lazim digunakan di negara Afganistan, Sri Lanka, Somalia dan Sudan yaitu bahasa Persia Afgani, Arab, Somali, Tamil/Sinhala. Dari 39 anak, hanya 10 orang yang bisa berbahasa Inggris. Dari seluruh petugas DCH hanya 3 orang yang fasih berbahasa Inggris. Penggunaan bahasa dalam komunikasi yang terjadi di DCH lebih banyak mengandalkan bantuan bahasa isyarat atau penerjemah dari UAM yang dapat berbahasa Inggris dan pekerja sosial yang dapat berbahasa Inggris.

Pada proses evaluasi, UAM masih banyak menimbang isi pesan persuasif dari beberapa faktor. Bila disampaikan dengan bahasa yang dimengerti, UAM cenderung menuruti pesan persuasif tersebut, selama tidak bertentangan dengan budaya asal mereka. Akar budaya asal yang dimiliki UAM sangat kuat karena UAM mayoritas masih berkumpul dan bersosialisasi dengan UAM senegara (cenderung berkelompok, terutama ketika UAM dari negara selain Afganistan mulai tinggal di DCH) atau kelompok imigran dewasa senegara yang tinggal di penampungan yang dekat dengan lokasi DCH. Proses deculturation sangat kuat sehingga ketika UAM menerima pesan persuasif yang isinya agar berlaku bertentangan dengan budaya asal mereka, UAM cenderung sangat defensif contohnya dengan mengutarakan "tidak ada yang salah dengan budaya kami, saya tidak mengganggu anda" ketika UAM diminta untuk makan dengan sendok atau lebih sopan.

Dalam proses evaluasi, dari 5 UAM yang diwawancara hanya 1 UAM yang memiliki motivasi lebih untuk mengembangkan diri selama di DCH. UAM menyatakan paham terhadap pilihan masa depan, namun pekerja sosial menyayangkan bahwa UAM tidak menunjukkan aksi mereka untuk mengembangkan diri terutama dengan mengikuti program-program yang ditawarkan sebagai fasilitas bagi UAM untuk meningkatkan diri seperti kursus bahasa Inggris. Dari proses evaluasi ini, motivasi dinilai sangat penting karena dari data wawancara memang hanya 1 UAM yang memiliki motivasi lebih saja yang dianggap oleh pekerja sosial sebagai UAM yang paling rajin dan aktif dalam kegiatan di DCH. Kurangnya motivasi ini berdasarkan temuan data adalah karena jumlah UAM yang dapat keluar dari Indonesia untuk bekerja ke negara dunia ketiga di tahun 2017 menurun drastis. Jumlah ini membuat para UAM menjadi kekurangan motivasi dan cenderung kehilangan harapan terhadap masa depan mereka.

Pada proses pemberian feedback dari persuadee kepada persuader, UAM sebagai persuadee mayoritas malas ketika dibujuk oleh pekerja sosial untuk mengikuti kegiatan kursus. Menurut persuader, mayoritas pesan-pesan persuasif yang disampaikan cenderung gagal atau tidak dituruti oleh UAM. Persuader sudah menggunakan beberapa model persuasif untuk mencari model yang tepat dalam memberikan pesan persuasif kepada persuadee, namun tetap gagal karena kurang motivasi lebih dari UAM yang menyebabkan mereka tidak konsisten dalam menjalankan sistem reward. 
Sebagian besar UAM masih belum bisa beradaptasi dengan budaya lokal di Medan. Proses adaptasi sempurna atau assimilation tidak berjalan karena beberapa faktor yaitu terjadi pembatasan terhadap proses enculturation yang terjadi antara UAM dengan lingkungan masyarakat di luar DCH, proses deculturation yang intens dari kelompok UAM senegara maupun antara UAM dengan kelompok imigran dewasa senegara lainnya, serta proses enculturation yang gagal dalam proses komunikasi persuasif antara pekerja sosial dengan UAM.

\section{SIMPULAN}

Dari penelitian ini dapat disimpulkan bahwa 1) Proses komunikasi persuasif yang dilakukan oleh petugas sosial kepada UAM di DCH tidak berhasil karena faktor noise atau gangguan komunikasi, kurangnya pemahaman UAM terhadap masa depan mereka (yang mengakibatkan kurangnya motivasi UAM dalam mengembangkan diri) dan pekerja sosial tidak memiliki kewajiban untuk membuat UAM hingga berhasil diterima wawancara oleh negara dunia ketiga. 2) Sebagian besar UAM masih belum bisa beradaptasi dengan budaya lokal di Medan, karena proses sosialisasi yang dibatasi oleh pekerja sosial dan petugas DCH karena menghindari kecemburuan sosial dan konflik dengan warga lingkungan sekitar diluar DCH. Proses adaptasi UAM terhadap budaya Indonesia UAM sendiri sedang berusaha untuk beradaptasi dengan UAM yang sekarang terdiri dari 4 negara yang berbeda, sejauh ini adaptasi tersebut sedang berjalan tanpa ada konflik besar.

\section{DAFTAR PUSTAKA}

De Vito, Joseph A. 2011.Komunikasi Antarmanusia, Edisi ke-5. Karisma Publishing Group. Jakarta.

Englund, Kate. 2011. Protecting the Human Rights of Unaccompanied Immigrant Minors. Advocates' Forum

Gudykunts, William B. \& Kim, Young Yun. 2003. Communicating with Strangers: An Approach to Intercultural Communication. McGraw Hill.

Ivashchenko, Kateryna. 2013. Eternal Return: Present-Day Problems Associated with Social Reintegration of Ukrainian Labor Migrants Arriving in Ukraine from EU (based on sociological research result). Research Report CARIM-East RR 2013/06. European Union. 
Mulhadi. 2014. Pelanggaran Hukum Nasional Indonesia Yang Dilakukan Oleh Pengungsi Yang Berada di Wilayah Indonesia (Suatu Tinjauan Hukum Pengungsi Internasional). Makassar. Fakultas Hukum Universitas Hasanuddin.

Pratam, Bayu. 2016. Adaptasi Budaya Etnis Rohingya dalam Budaya Masyarakat Aceh Timur dan Kota Langsa. Universitas Syiah Kuala. Aceh.

Sumirat, Soleh \& Suryana, Asep. 2014. Komunikasi Persuasif. Universitas Terbuka. Banten. 